\title{
A New Method for Detecting Input Phase Lack of Power Unit in Cascade High Voltage Inverter
}

\author{
Shibao Qian ${ }^{1}$, Chunsong $\mathrm{Liu}^{2}$, Xuan $\mathrm{Hu}^{2, *}$ \\ ${ }^{1}$ Guodian Nanjing Automation Co. Ltd., Nanjing, China \\ ${ }^{2}$ Nanjing SAC New Energy Technology Co., Ltd., Nanjing, China \\ ${ }^{*}$ Corresponding author
}

\begin{abstract}
This paper presents a detection method of input phase lack of power unit in cascaded high voltage inverter. The method determine the input phase lack of power unit in cascaded high voltage inverter through the detection of primary negative sequence current of phase shifting transformer. The start-up threshold is set by the negative sequence input current of the cascaded high voltage inverter and input phase lack is judged by the actual output power. The new phase detection method does not need to add extra circuit of all power units to realize the phase detection in input side of each power unit, so that the complexity of fault detection circuit is reduced, thus the reliability of high voltage converter is increased.
\end{abstract}

Keywords-component; Cascaded High Voltage Inverter; Phase Lack; Power Unit

\section{INTRODUCTION}

With the wide application of cascaded high voltage inverter in electric power, metallurgy, petroleum, chemical industry and other important occasions, it puts forward higher requirements for the stability of cascaded high voltage inverter. When the input phase lack of power unit in cascaded high-voltage inverter happens, the inverter should send alarm; otherwise the operation with input phase lack in the power unit in a long time will cause the damage of the power unit and transformer winding, and the shutdown of the entire system, thus affecting the production.

\section{Traditional Phase Lack Protection}

The topology of Cascaded High Voltage Inverter is shown in Figure I. The output power of each power unit is $\frac{1}{3 n}$ of the total power of Cascaded High Voltage Inverter $(r:$ the number of the power unit in one phase cascaded high-voltage inverter). Due to the large number of the power unit, input phase fault of one power unit input have little effect on the output power of the high voltage converter. So when input phase fault of one power unit occurs, and cascaded high voltage inverter can still continue running for a long time with small output load. The duration of the operation depends on whether the missing phase power unit input is in the overload state.

The common reasons of power unit input phase fault in cascaded high voltage inverter include input fuse fusing, phase shift transformer winding damage and connection cable break of transformer winding and power unit input. The main detection method of cascaded high voltage inverter power unit input used by most manufacturers is that each power unit has phase detection circuit, which can protect fusible core of the power input unit. Through step-down, isolation, detection, indication and signal output circuit in the power unit, input phase fault is detected.

The method for detecting the lack of phase in the input side of the power unit needs to add a phase detection circuit in the inner part of each power unit to judge the fault. Because cascaded high voltage inverter is composed of a plurality of power units, increasing the phase detection in the way of each power unit increases the possibility of its own failure, reducing the reliability of Cascaded High Voltage inverter. The negative sequence current detection of Cascaded High Voltage Inverter in the input side of transformer determine whether the phase input of cascaded high voltage inverter power unit, without increasing the phase detection device in each power unit, increasing the reliability of the system.

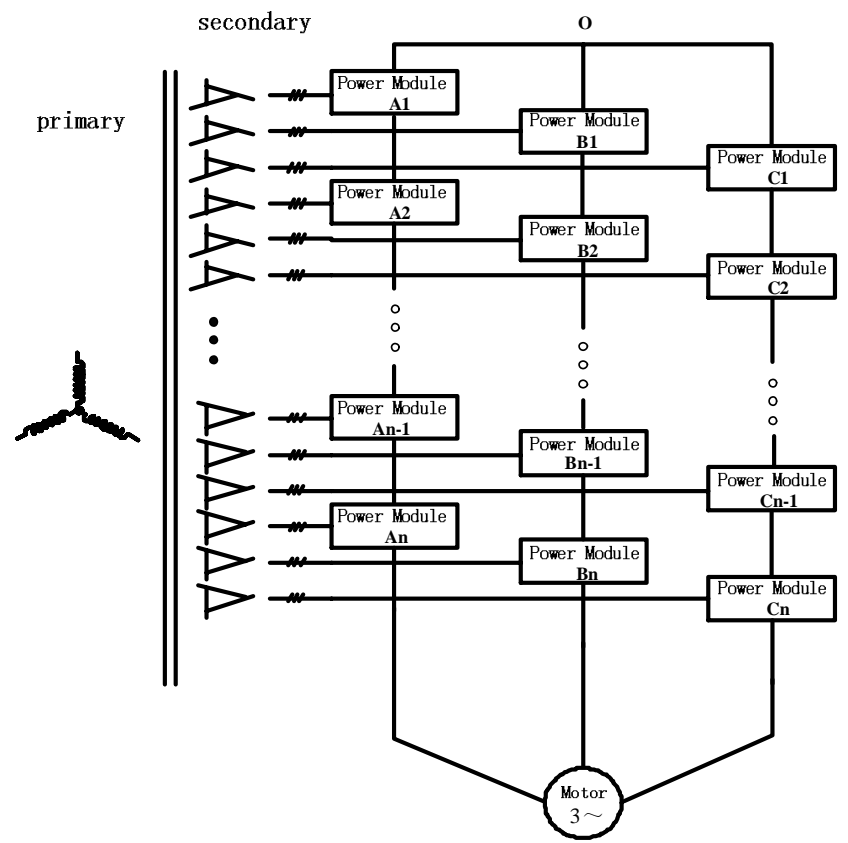

FIGURE I. THE TOPOLOGY OF CASCADED HIGH VOLTAGE INVERTER. 


\section{A New Phase Detection Method Based ON CURRENT DETECTION OF TRANSFORMER}

The primary power transformer is equal to the summary power of all secondary sides. With the voltage and power of primary side, calculating current of secondary side to the primary side, current of each secondary side is $\frac{I}{3 n}$ ( $I$ : current primary).

The method also comprises the following steps: setting the corresponding negative sequence current protection starting threshold according to the power characteristic of the primary side of the phase shifting transformer. When input phase fault of a power unit occurs, the secondary side of the transformer will generate a negative sequence current component, and the negative sequence current component is coupled to the primary side. Negative sequence current will be generated in the primary current. In power system protection, the negative sequence current protection setting value is $(50 \%$ $60 \%) I_{n}\left(I_{n}\right.$ : the primary side current of transformer). Due to the characteristics of the primary and secondary side of the phase shift transformer, the starting value of the negative sequence current protection of the cascaded high voltage inverter is $\frac{I}{6 n}$. The sequence is shown in Figure II.

The method also includes judging the actual output power of Cascaded High Voltage inverter. When the Cascaded High Voltage Inverter provides three-phase motor drive power, motor operates at different frequencies, the output power of inverter will be different (output power can be obtained by the inverter output voltage and output current). For different frequencies, the input current of the inverter is $I=\frac{P}{P_{n}} I_{n}$, which is the primary current of the transformer $\left(P_{n}\right.$ : the rated power of the cascaded high voltage inverter). The starting value of negative sequence current protection of Cascaded High Voltage inverter is $\frac{P I_{n}}{6 n P_{n}}$.

According to this method, a simulation model is built to simulate the situation of negative sequence current in different frequency.

\section{SimUlation VerificATION}

With the simulation of $1250 \mathrm{~kW}$ inverter working at $40 \mathrm{~Hz}$ for the wind turbine pump load, the frequency is $80 \%$ of rated frequency, the power is approximately equal to 0.512 times of rated power, the output voltage is changed to a factor of 0.8 , the output current is changed to a factor of 0.64 , and the input current is changed to a factor of 0.512 times. Assume that the output power factor remains constant.

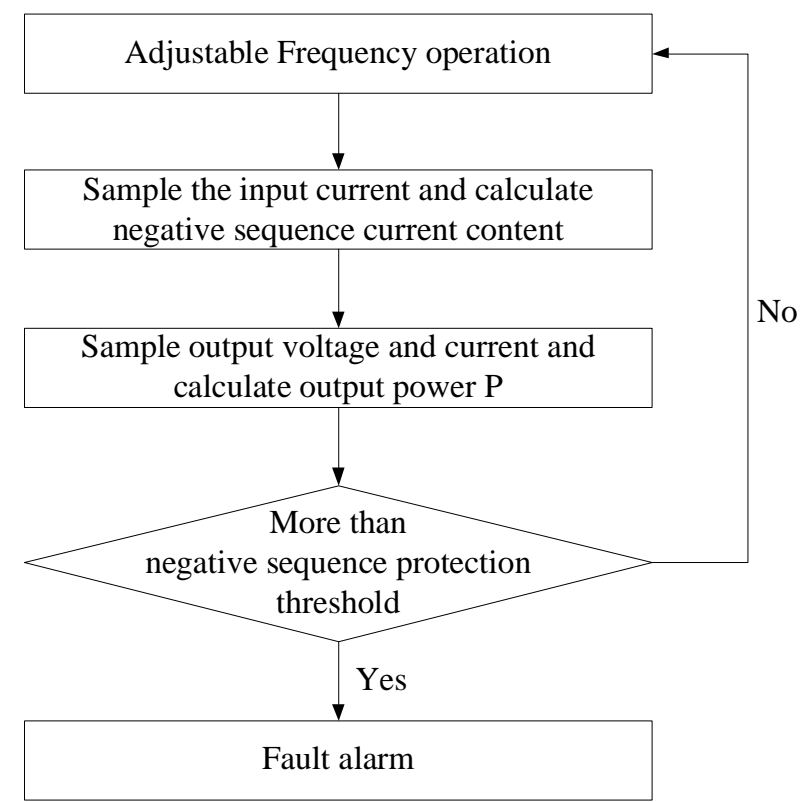

FIGURE II. FLOW OF THE NEW PHASE DETECTION METHOD BASED ON CURRENT DETECTION OF TRANSFORMER

Figure III is the input and output situation of the inverter. And the input voltage is $6000 \mathrm{~V}$, the input current is $70 \mathrm{~A}$. Output voltage is $4790 \mathrm{~V}$, output current is $96 \mathrm{~A}$.

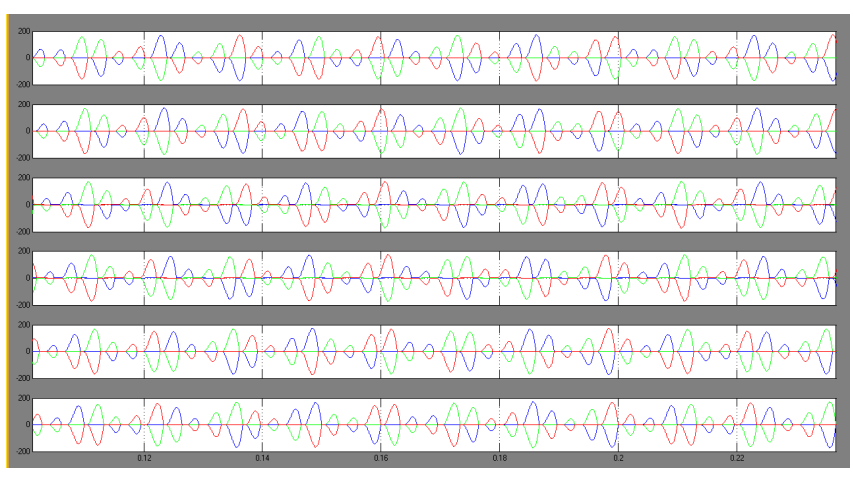

FIGURE III. INPUT CURRENT OF A1-C WITHOUT INPUT PHASE FAULT

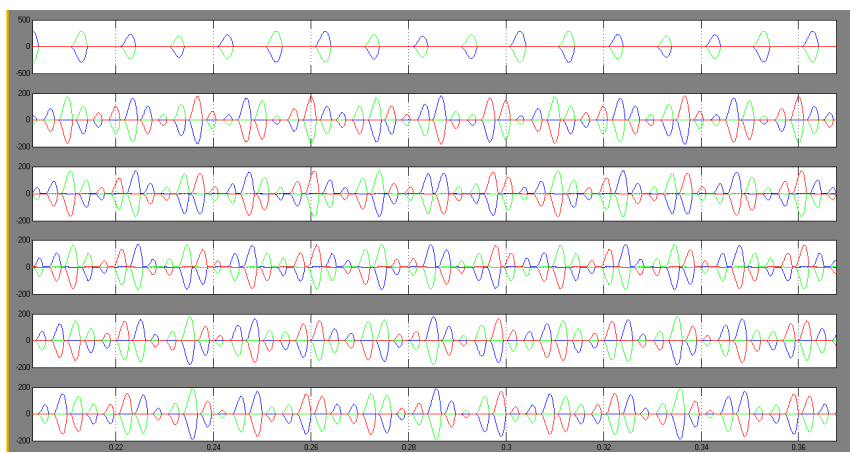

FIGURE IV. INPUT CURRENT OF A1-C WITH INPUT PHASE FAULT 


\section{A. Input Phase Fault of One Power Unit}

The negative sequence component of input current is less than 0.09A. When the input phase of a power unit is out of phase, the fluctuation range of the negative sequence component of the input current is from $2.5 \mathrm{~A}$ to $6 \mathrm{~A}$.

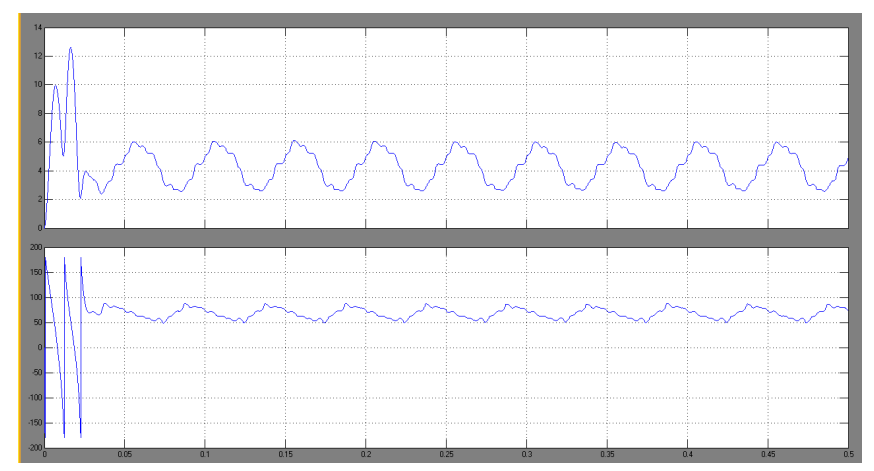

FIGURE V. NEGATIVE SEQUENCE COMPONENT OF INPUT CURRENT WITH A1-C INPUT PHASE FAULT

\section{B. Phase Lack Fault of Two Power Units}

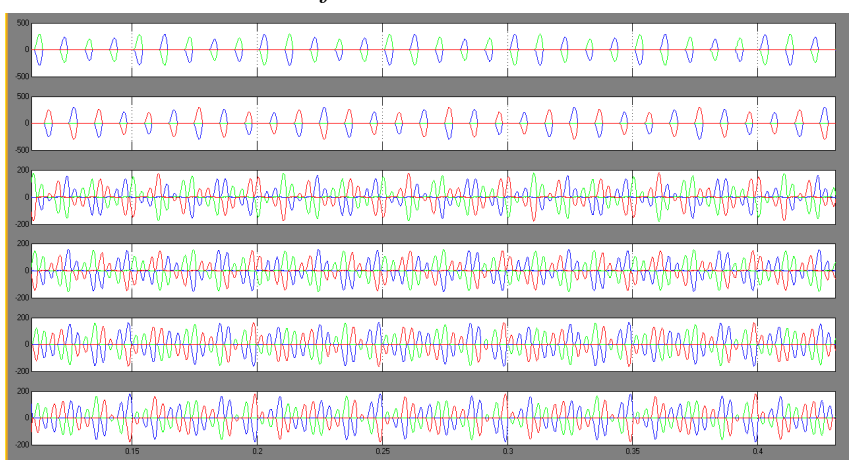

FIGURE VI. INPUT CURRENT OF A1-C WITH INPUT PHASE FAULT

When the input phase fault of A1-c and A2-b power unit happens, the fluctuation range of the negative sequence component of the input current is from $1.5 \mathrm{~A}$ to $6 \mathrm{~A}$.

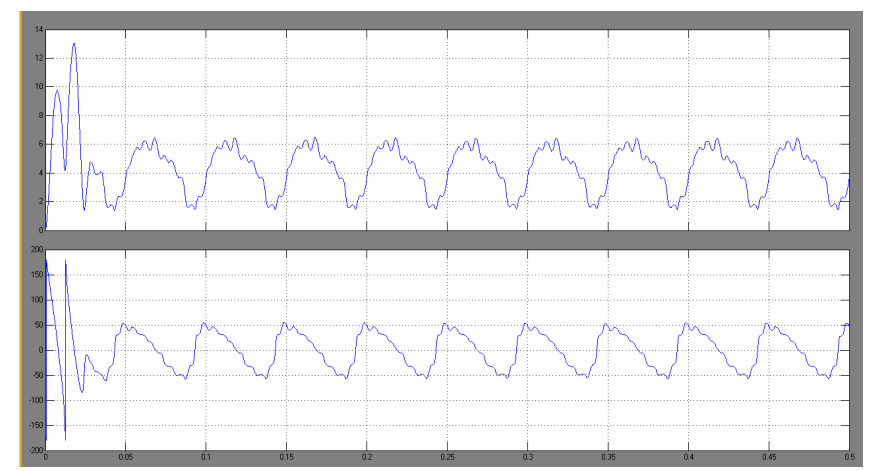

FIGURE VII. NEGATIVE SEQUENCE COMPONENT OF INPUT CURRENT WITH A1-C、A2-B INPUT PHASE FAULT

The simulation results show that when a power unit is out of phase, it can be used to measure the negative sequence current component on the original side to determine input phase fault. When the two elements are out of phase, the negative sequence current may be close to zero due to the synthesis of the two elements.

\section{SUMMARY}

The beneficial effect of the invention is to realize the input of cascaded high voltage inverter power unit phase detection, without increasing the phase detection circuit in the interior of each power unit, processing phase detection of cascaded high voltage inverter power input unit through the software, improves the reliability of the system.

\section{REFERENCES}

[1] C. Jian, Power Electronics-Power Electronic Transformation And Control Technology[M]. Higher Education Press, 2004.

[2] C. Boshi, Automatic Control System For Electric Drive. [M]. Machinery Industry Press, 2008.

[3] P. Hammond. A new approach to enhance power quality for medium voltage AC drives[J]. IEEE Trans. Ind. Applicat, 2003, 39(2): 202 208.

[4] M. Marchesoni, M. Mazzucchelli and S. Tenconi. A Non-conventional Power Converter for Plasma Stabilization[J]. IEEE Proc. of IEEE-PESC', 1988: 122-129. 